\title{
Effect of granulocyte-macrophage colony- stimulating factor on candidacidal activity of neutrophils, monocytes or monocyte-derived macrophages and synergy with fluconazole
}

\author{
U. NATARAJAN*, N. RANDHAWA*, E. BRUMMER* ${ }^{*}$ and D. A. STEVENS*† \\ * Division of Infectious Diseases, Department of Medicine, Santa Clara Valley Medical Center and California \\ Institute for Medical Research, 751 South Bascom Ave, San Jose, CA 95128-2699 and †Stanford University \\ School of Medicine, Stanford, CA 94305, USA
}

\begin{abstract}
The effect of in-vitro granulocyte-macrophage colony-stimulating factor (GM-CSF) treatment of neutrophils, monocytes or monocyte-derived macrophages (MDM) on candidacidal activity was tested. Synergy of effector cells with fluconazole (FCZ) for enhanced killing was also investigated. Incubation of neutrophils with GM-CSF $0.67 \mu \mathrm{g} / \mathrm{L}$ plus Candida albicans Sh27 for $24 \mathrm{~h}$ significantly increased candidacidal activity (36\% versus $74 \%$ ). Synergy with $\mathrm{FCZ}$ for killing was also significantly increased from $93 \%$ to $97 \%$ when neutrophils were incubated with GM-CSF. Monocytes cultured with GM-CSF and $C$. albicans for $24 \mathrm{~h}$ had significantly increased fungistatic activity compared to controls and synergy with FCZ for killing was significantly enhanced from $\mathbf{4 0 \%}$ to $59 \%$. Monocytes cultured for 3 days with GM-CSF had increased fungistatic activity compared to control MDM and showed synergy with FCZ for significantly enhanced killing (46\%) compared to control MDM (12\%).
\end{abstract}

\section{Introduction}

The molecular biology and functions of granulocytemacrophage colony-stimulating factor (GM-CSF) have been described by Metcalf [1]. GM-CSF purified from mitogen-stimulated human $T$ cells was shown to stimulate neutrophil function $[2,3]$. GM-CSF produced by recombinant DNA technology has been used clinically in AIDS patients $[4,5]$. Treatment of neutrophils or monocytes in vitro with rhGM-CSF increased their fungicidal activity for Candida albicans $[6,7]$; this was associated with enhanced superoxide anion production [8].

A recent study reported that fluconazole, a triazole that is only fungistatic for C. albicans showed synergy with human neutrophils, monocytes or monocyte-derived macrophages (MDM) for increased candidacidal activity $[9,10]$. Those results helped to explain the curative efficacy of fluconazole in vivo. The present study postulates that if GM-CSF-treated neutrophils, monocytes or MDM have augmented fungicidal activity, they should also show synergy with fluconazole for greater candidacidal activitiy compared to controls.

Received 1 April 1997; accepted 8 August 1997.

Corresponding author: Dr E. Brummer.

\section{Materials and methods}

\section{Candida albicans}

C. albicans isolate Sh27 (ATCC 56882) and clinical isolates 94-159 and 94-186, susceptible to fluconazole $(\mathrm{MIC}<0.5 \mathrm{mg} / \mathrm{L})[9,10]$ were used in these experiments. Yeast cells were grown on blood agar at $35^{\circ} \mathrm{C}$ for $48 \mathrm{~h}$. Yeast cells were washed in saline, diluted, counted and suspended in RPMI-1640 containing penicillin $100000 \mathrm{U} / \mathrm{L}$, streptomycin $100 \mathrm{mg} / \mathrm{L}$ and fresh frozen human serum (HS) $10 \%$ (5\% in some experiments) (CTCM). Dilutions of the suspension were plated on blood agar plates in quadruplicate at time zero to determine the number of cfu in the inoculum.

\section{Effector cells}

Polymorphonuclear neutrophil leucocytes (PMNL) and peripheral blood mononuclear cells (PBMC) were isolated from heparinised blood by dextran-70 (6\%) sedimentation followed by density gradient centrifugation on Histopaque 1077 (Sigma). PMNL were suspended to $2 \times 10^{6} / \mathrm{ml}$ in CTCM and dispensed $0.1 \mathrm{ml}$ per microtest plate well (Corning \#25860, Corning, NY, USA). PBMC at $5 \times 10^{6} / \mathrm{ml}$ of CTCM with or without GM-CSF were dispensed $0.1 \mathrm{ml}$ per microtest well (half area wells, Corning \#25870) then 
incubated for $2 \mathrm{~h}$ at $37^{\circ} \mathrm{C}$ in $\mathrm{CO}_{2} 5 \%$ in air in a $\mathrm{CO}_{2}$ incubator. After incubation, non-adherent cells were aspirated and the monolayer was washed once with RPMI-1640. In some experiments, quadruplicate sets of adherent cells (monocytes) were incubated in CTCM with or without GM-CSF for 3 days to obtain monocyte-derived macrophages (MDM).

\section{GM-CSF}

Recombinant human GM-CSF, Leukine (Sargramostin), was produced and supplied by Immunex Corp., Seattle, WA, USA. GM-CSF $\left(1.5 \times 10^{8} \mathrm{IU} / \mathrm{mg}\right)$ was diluted to $7.5 \times 10^{5} \mathrm{IU}(5 \mathrm{mg} / \mathrm{L})$ in RPMI-1640 and $0.1-\mathrm{ml}$ portions were stored at $-80^{\circ} \mathrm{C}$.

\section{Fluconazole}

Fluconazole (FCZ) was supplied by Pfizer, Groton, CT, USA. FCZ powder was dissolved in distilled water at $2 \mathrm{~g} / \mathrm{L}$ and stored at $4^{\circ} \mathrm{C}$. Desired dilutions were made from the FCZ stock in RPMI-1640.

\section{Effector cell assays}

Effector cell cultures were challenged with $0.1 \mathrm{ml}$ of a suspension of yeast cells in CTCM. Some sets of quadruplicate cultures received $0.01 \mathrm{ml}$ of an appropriate dilution of GM-CSF. Other sets of quadruplicate cultures received $0.01 \mathrm{ml}$ of $\mathrm{FCZ}$ to give a final concentration of $1 \mathrm{mg} / \mathrm{L}$ of both GM-CSF and FCZ. After incubation for $24 \mathrm{~h}$ at $37^{\circ} \mathrm{C}$ in $\mathrm{CO}_{2} 5 \%$, cultures were harvested with distilled water to lyse human cells and release yeast cells. Appropriate dilutions of harvested material were plated on blood agar, colony counts were made after incubation for $48 \mathrm{~h}$ at $35^{\circ} \mathrm{C}$, and $\mathrm{cfu} /$ culture were calculated.

\section{Quantitative analysis}

Human serum (10\%) in RPMI-1640 inhibits the growth of C. albicans by $>90 \%$ compared to growth in RPMI-1640 alone [9]. Typical morphology of growth in CTCM was short budding pseudohyphae. In co-cultures with effector cells no extracellular growth of $C$. albicans was evident. When growth in CTCM was harvested, pelleted and examined by microscopy, $92 \%$ of the fungal units (cfu) of strain $\mathrm{Sh} 27$ consisted of one to two cells. The average number of cells per fungal unit for strain 94-159 was 1.7 and for strain 94-186 it was 2.47 . The number of cells/unit was not different before challenge of cells or after harvest from effector cells lysed with distilled water.

Inhibition of growth, or percentage of fungistasis, was determined by the formula: [1-(experimental cfu/ control cfu $] \times 100$. Candidacidal activity, or percentage reduction of inoculum $\mathrm{cfu}$, was calculated by the formula: [1-(experimental cfu/inoculum cfu)] $\times 100$. Where killing occurred, e.g., experimental cfu $\leqslant$ inoculum cfu, fungistasis was defined as $100 \%$. Student's $t$ test was used for statistical analysis of data and significance was set at $\mathrm{p}<0.05$.

\section{Results \\ Effect of GM-CSF on PMN}

Incubation of PMNL with GM-CSF $(0.67$ or $3.33 \mu \mathrm{g} / \mathrm{L})$ and $C$. albicans for $24 \mathrm{~h}$ resulted in enhanced killing $(\mathrm{p}<0.01)$ compared to killing in PMNL cultures without GM-CSF, $74 \%$ and $68 \%$ versus $36 \%$ (Table 1). As previously reported, PMNL showed synergy with FCZ for significantly increased killing of C. albicans and that was confirmed here, e.g., $36 \%$ versus $93 \%$ killing. Moreover, PMNL in the presence of GM-CSF showed synergy with FCZ to a significantly greater extent for killing than did PMNL plus $\mathrm{FCZ}, 4.8 \times 10^{2}\left(\mathrm{SD} 0.9 \times 10^{2}\right)$ and $3.4 \times 10^{2}(\mathrm{SD}$ $\left.1 \times 10^{2}\right)$ cfu versus $8.1 \times 10^{2}\left(\mathrm{SD} 1.3 \times 10^{2}\right) \mathrm{cfu}$ (Table 1).

In a suboptimal system in which CTCM contained only 5\% human serum, PMNL failed to kill $C$. albicans in the 24-h assay. The effect of GM-CSF $(3.33 \mu \mathrm{g} / \mathrm{L})$ on PMNL was amplified in this system and killing increased from $0 \%$ to $75 \%$ (Table 2). Under these suboptimal conditions, PMNL and FCZ showed synergy only for a low level of killing (17\%). On the other hand, PMNL with GM-CSF showed synergy with FCZ for a significantly increased level of killing, e.g., 17\% versus 98\% (Table 2).

Table 1. Effect of GM-CSF on neutrophil activity against C. albicans Sh27 and synergy with fluconazole

\begin{tabular}{|c|c|c|c|c|c|}
\hline Treatment* & GM-CSF $\mu \mathrm{g} / \mathrm{L}$ & $\mathrm{FCZ} 1 \mathrm{mg} / \mathrm{L}$ & Mean (SD) cfu $\times 10^{3}$ & Killing (\%) & $\mathrm{p}$ value \\
\hline Inoculum & & & $11.6(0.58)$ & & \\
\hline CFCM $10 \%$ HS & 0 & - & $75.0(5.7)$ & & \\
\hline \multirow[t]{3}{*}{ PMNL } & 0 & - & $7.5(1.2)$ & 36 & $* *$ \\
\hline & 0.67 & - & $3.0(1.0)$ & 74 & $<0.01^{\ddagger}$ \\
\hline & 3.33 & - & $3.8(0.90)$ & 68 & $<0.01^{\S}$ \\
\hline CTCM $10 \%$ HS & 0 & + & $10.4(1.6)$ & 10 & $>0.05$ \\
\hline \multirow[t]{3}{*}{ PMNL } & 0 & + & $0.8(0.13)$ & 93 & $<0.01$ \\
\hline & 0.67 & + & $0.5(0.95)$ & $96^{\dagger}$ & $<0.01<0.01^{\ddagger}$ \\
\hline & 3.33 & + & $0.3(0.10)$ & $97^{\dagger}$ & $<0.01<0.01^{\S}$ \\
\hline
\end{tabular}

*PMNL were co-cultured with C. albicans in CTCM with or without GM-CSF and with or without fluconazole (FCZ) in quadruplicate 24-h cultures.

${ }^{\dagger}$ Killing by PMNL + FCZ compared to PMNL + GM-CSF + FCZ, p $<0.01$.

${ }^{\ddagger}$ Show two pairs of comparisons.

**Baseline value for comparisons. 
Table 2. Effect of GM-CSF on neutrophil activity against C. albicans Sh27 and synergy with fluconazole (FCZ) under suboptimal conditions

\begin{tabular}{|c|c|c|c|c|c|}
\hline Treatment* & GM-CSF $\mu \mathrm{g} / \mathrm{L}$ & $\mathrm{FCZ} 1 \mathrm{mg} / \mathrm{L}$ & Mean $(\mathrm{SD}) \mathrm{cfu} \times 10^{3}$ & Killing (\%) & $\mathrm{p}$ value \\
\hline Inoculum & & & $0.5(0.1)$ & & \\
\hline CTCM 5\% HS & 0 & - & $28.3(3.5)$ & & \\
\hline \multirow[t]{2}{*}{ PMNL } & 0 & - & $0.5(0.1)$ & 0 & $* *$ \\
\hline & 3.3 & - & $0.1(0.03)$ & 75 & $<0.01^{\ddagger}$ \\
\hline CTCM 5\% HS & 0 & + & $1.6(0.2)$ & 0 & \\
\hline \multirow[t]{2}{*}{ PMNL } & 0 & + & $0.4(0.03)$ & $17^{\dagger}$ & $<0.05$ \\
\hline & 3.3 & + & $0.01(0.01)$ & $98^{\dagger}$ & $<0.01<0.01^{\ddagger}$ \\
\hline
\end{tabular}

*PMNL were co-cultured with $C$. albicans in CTCM containing 5\% human serum with or without GM-CSF and with or without FCZ in quadruplicate 24-h cultures.

${ }^{\dagger}$ Killing by PMNL + GM-CSF compared to killing by PMNL + GM-CSF + FCZ, p $<0.01$.

$* *,{ }^{\ddagger}$ See footnote to Table 1 .

When isolates 94-159 and 94-186 were tested, GMCSF $(0.67 \mu \mathrm{g} / \mathrm{L})$-treated PMNL increased killing from $49 \%$ to $62 \%$ and from $73 \%$ to $84 \% \quad(p<0.01)$, respectively. Moreover, GM-CSF-treated PMNL showed synergy with $\mathrm{FCZ}$ for significantly enhanced killing of isolate $94-159$ from $81 \%$ to $85 \%$ $(\mathrm{p}<0.05)$. Synergic killing of isolate $94-186$ by PMNL + FCZ was $96 \%$ and this almost complete killing could not be increased by GM-CSF-treated PMNL + FCZ

\section{Effect of GM-CSF on monocytes}

When monocytes were co-cultured with GM-CSF $(0.67 \mu \mathrm{g} / \mathrm{L})$ and $C$. albicans for $24 \mathrm{~h}$, growth was inhibited compared to growth in monocyte cultures without GM-CSF $(\mathrm{p}<0.01)$ (Table 3$)$. As previously reported, monocytes showed synergy with $\mathrm{FCZ}$ for killing $C$. albicans and here killing was 40\%; monocytes with GM-CSF and FCZ caused significantly increased killing, 59\% (Table 3). Similar results were obtained in a second experiment.

\section{Effect of GM-CSF on MDM}

When monocytes were cultured for 3 days in CTCM containing human serum $10 \%$ with or without GM-CSF $(0.67 \mu \mathrm{g} / \mathrm{L})$ both types of MDM were highly fungistatic, but not fungicidal for $C$. albicans (Table 4). It can be noted that MDM from GM-CSF cultures caused increased fungistasis, $1.9 \times 10^{3}$ (SD $\left.0.2 \times 10^{3}\right) \mathrm{cfu}$ versus $3.8 \times 10^{3}\left(\mathrm{SD} 0.3 \times 10^{3}\right) \mathrm{cfu}$. MDM showed synergy with FCZ for killing $C$. albicans (12\%). Moreover, synergic killing increased to $46 \%$ when GMCSF MDM were cultured with FCZ and $C$. albicans (Table 4).

When monocytes were cultured under suboptimal conditions, e.g., CTCM containing human serum 5\%, MDM from GM-CSF cultures had significantly in-

Table 3. Effect of GM-CSF on monocyte activity against C. albicans Sh27 and synergy with fluconazole (FCZ)

\begin{tabular}{lccccc}
\hline Treatment $^{*}$ & GM-CSF $\mu \mathrm{g} / \mathrm{L}$ & FCZ $1 \mathrm{mg} / \mathrm{L}$ & Mean $(\mathrm{SD}) \mathrm{cfu} \times 10^{3}$ & Killing (\%) & $\mathrm{p}$ value \\
\hline Inoculum & & & $1.5(0.1)$ & & \\
CTCM 10\% HS & 0 & - & $153.0(50.0)$ & 0 & $* *$ \\
Monocytes & 0 & - & $2.2(0.1)$ & 0 & $<0.01^{\ddagger}$ \\
CTCM 10\% HS & 0.67 & - & $1.5(0.1)$ & 0 & $<.4(1.0)$ \\
Monocytes & 0 & + & $0.9(0.1)$ & $40^{\dagger}$ & $<0.01$ \\
& 0.67 & + & $0.6(0.1)$ & $59^{\dagger}$ & $<0.01<0.01^{\ddagger}$ \\
\hline
\end{tabular}

*Monocytes were co-cultured with C. albicans with or without GM-CSF and with or without FCZ in quadruplicate 24-h cultures. ${ }^{\dagger}$ Killing by monocytes $+\mathrm{FCZ}$ compared to killing by moncytes $+\mathrm{GM}-\mathrm{CSF}+\mathrm{FCZ}, \mathrm{p}<0.01$.

**, ${ }^{+}$See footnote to Table 1 .

Table 4. Effect of GM-CSF on monocyte-derived macrophages (MDM) against C. albicans Sh27 and synergy with fluconazole (FCZ)

\begin{tabular}{|c|c|c|c|c|c|}
\hline Treatment* & GM-CSF $\mu \mathrm{g} / \mathrm{L}$ & $\mathrm{FCZ} 1 \mathrm{mg} / \mathrm{L}$ & Mean $(\mathrm{SD}) \mathrm{cfu} \times 10^{3}$ & Killing (\%) & $\mathrm{p}$ value \\
\hline Inoculum & & & $1.5(0.05)$ & & \\
\hline CTCM $10 \%$ HS & 0 & - & $96.7(10)$ & & \\
\hline $\mathrm{MDM}^{*}$ & 0 & - & $3.7(0.3)$ & 0 & $* *$ \\
\hline & 0.67 & - & $1.8(0.2)$ & 0 & $<0.01$ \\
\hline CTCM $10 \%$ HS & 0 & + & $8.6(1.7)$ & 0 & \\
\hline MDM & $\begin{array}{l}0 \\
0.67\end{array}$ & $\begin{array}{l}+ \\
+\end{array}$ & $\begin{array}{l}1.3(0.09) \\
0.8(0.16)\end{array}$ & $\begin{array}{l}12^{\dagger} \\
46^{\dagger}\end{array}$ & $\begin{array}{l}<0.01^{\ddagger} \\
<0.01<0.01^{\ddagger}\end{array}$ \\
\hline
\end{tabular}

${ }^{*}$ MDM were co-cultured with $C$. albicans in CTCM with or without GM-CSF and with or without FCZ in quadruplicate 24-h cultures. ${ }^{\dagger} \mathrm{MDM}+\mathrm{FCZ}$ versus FCZ alone, $\mathrm{p}<0.01, \mathrm{MDM}+\mathrm{GM}-\mathrm{CSF}+\mathrm{FCZ}$ versus $\mathrm{MDM}+\mathrm{GM}-\mathrm{CSF}, \mathrm{p}<0.01$.

**, ${ }^{\ddagger}$ See footnote to Table 1 . 
creased fungistatic activity compared to control MDM, e.g., $1.9 \times 10^{3}\left(\mathrm{SD} 0.6 \times 10^{3}\right)$ versus $4.8 \times 10^{3}(\mathrm{SD}$ $1.7 \times 10^{3}$ ) cfu (Table 5). Control MDM failed to show synergy with FCZ for killing $C$. albicans although fungistasis was markedly improved; however, GM-CSF MDM showed synergy with FCZ and, in combination, killed $75 \%$ of the yeast cells. (Table 5).

\section{Discussion}

This report shows that GM-CSF enhances the antifungal activity of PMNL in a 24-h assay. Richardson et al. found similar results with a different experimental design [6]; adherent PMNL were pretreated with GMCSF for $1 \mathrm{~h}$, then challenged for $3 \mathrm{~h}$ and enhanced killing of $C$. albicans was measured as reduced survival of the inoculum.

PMNL activated by GM-CSF have increased capacity to show synergy with $\mathrm{FCZ}$, resulting in significantly enhanced killing of $C$. albicans compared to controls.

Sixty percent of $C$. albicans yeast cells are killed by monocytes in 2-h assays [11]. Depending on inoculum size and donor variations it has been found that in 24-h assays there can be reduction of inoculum cfu or, as reported here, fungistasis. We postulate that in 24-h co-cultures, yeast cells surviving the initial killing multiply so that the number of cfu at $24 \mathrm{~h}$ is greater than at the time of inoculation.

The present study showed that co-culture of monocytes with GM-CSF for $24 \mathrm{~h}$ enhanced their fungistatic activity for $C$. albicans. Smith et al. used a different protocol and an indirect method for measuring antifungal activity and reported similar results [7]. They exposed monocytes to GM-CSF $(500 \mathrm{U} / \mathrm{ml})$ for $14 \mathrm{~h}$, challenged the monocytes with ${ }^{3} \mathrm{H}$-leucine-labelled $C$. albicans for $4 \mathrm{~h}$ and measured increased antifungal activity by ${ }^{3} \mathrm{H}$-leucine release. Moreover, the present study demonstrated that GMCSF induced increased ability of monocytes to show synergy with FCZ for killing C. albicans compared to controls.

While others have reported that GM-CSF activation of
MDM increased antimicrobial activity against $\mathrm{Myco}$ bacterium avium, Leishmania donovani and Trypanosoma cruzi, this study reports for the first time that GM-CSF increased the fungistatic activity of MDM for C. albicans [12-14].

A previous study demonstrated that MDM shows synergy with FCZ for killing C. albicans [10]. This study confirms those results and demonstrates that GM-CSF treatment augments the capacity of MDM to show synergy with FCZ for increased candidacidal activity.

These results provide a rationale for combination therapy with GM-CSF and fluconazole in the treatment of fungal infection.

\section{References}

1. Metcalf D. The molecular biology and functions of the granulocyte-macrophage colony-stimulating factors. Blood 1986; 67: 257-267.

2. Gasson JC, Weisbart RH, Kaufman SE et al. Purified human granulocyte-macrophage colony-stimulating factor: direct action on neutrophils. Science 1984; 226: 1339-1342.

3. Weisbart RH, Kwan L, Golde DW, Gasson IC. Human GMCSF primes neutrophils for enhanced oxidative metabolism in response to the major physiological chemoattractants. Blood 1987; 69: 18-21.

4. Wong GG, Witek JS, Temple PA et al. Human GM-CSF: molecular cloning of the complementary DNA and purification of the natural and recombinant proteins. Science 1985; 228: $810-815$.

5. Groopman JE, Mitsuyasu RT, DeLeo MH, Oette DH, Golde DW. Effect of recombinant human granulocyte-macrophage colony-stimulating factor on myelopoiesis in the acquired immunodeficiency syndrome. $N$ Eng $J$ Med 1987; 317: 593-598

6. Richardson MD, Brownlie CED, Shankland GS. Enhanced phagocytosis and intracellular killing of Candida albicans by GM-CSF activated human neutrophils. J Med Vet Mycol 1992; 30: $433-441$

7. Smith PD, Lamerson CL, Banks $\mathrm{S}$ et al. Granulocytemacrophage colony-stimulating factor augments human monocyte fungicidal activity for Candida albicans. $J$ Infect Dis 1990; 161: 999-1005.

8. Nathan CF. Respiratory burst in adherent human neutrophils: triggering by colony-stimulating factors CSF-GM and CSF-G Blood 1989; 73: 301-306.

9. Brummer E, Stevens DA. Synergy of human neutrophils with fluconazole in killing Candida species. Mycopathologia 1996; 134: $115-120$.

10. Garcha UK, Brummer E, Stevens DA. Synergy of fluconazole with human monocytes or monocyte-derived macrophages for killing Candida species. J Infect Dis 1995; 172: 1620-1623.

Table 5. Effect of GM-CSF on monocyte-derived macrophages activity against C. albicans Sh27 and synergy with fluconazole (FCZ)

\begin{tabular}{lcccc}
\hline Treatment* & GM-CSF $\mu \mathrm{g} / \mathrm{L}$ & FCZ $1 \mathrm{mg} / \mathrm{L}$ & Mean (SD) cfu $\times 10^{3}$ & Killing (\%) \\
\hline Inoculum & & & $1.3(0.08)$ & \\
CTCM 5\% HS & 0 & - & $192.5(3.0)$ & 0 \\
MDM & 0 & - & $4.8(1.7)$ & 0 \\
& 0.67 & - & $1.9(0.06)$ & 0 \\
CTCM 5\% HS & 0 & + & $5.9(1.0)$ & 0 \\
MDM & 0 & + & $1.8(0.05)$ & 0 \\
& 0.67 & + & $0.3(0.06)$ & 75 \\
\hline
\end{tabular}

${ }^{*}$ MDM were co-cultured with $C$. albicans in CTCM containing $5 \%$ human serum with or without GM-CSF and with or without FCZ in quadruplicate 24-h cultures. MDM + FCZ versus FCZ, $\mathrm{p}<0.01 ; \mathrm{MDM}+\mathrm{GM}-\mathrm{CSF}+\mathrm{FCZ}$ versus FCZ, or versus $\mathrm{MDM}+\mathrm{GM}-\mathrm{CSF}$, $\mathrm{p}<0.01$. ${ }^{* *}$, ${ }^{\ddagger}$ See footnote to Table 1 . 
11. Maródi L, Forehand JR, Johnston RB. Mechanisms of host defense against Candida species II. Biochemical basis for the killing of Candida by mononuclear phagocytes. $J$ Immunol 1991; 146: 2790-2794.

12. Bermudez LE, Young LS. Recombinant granulocytemacrophage colony-stimulating factor activates human macrophages to inhibit growth or kill Mycobacterium avium complex. J Leukoc Biol 1990; 48: 67-73.

13. Weiser WY, Van Niel A, Clark SC, David JR, Remold HG.
Recombinant human granulocyte macrophage colony-stimulating factor activates intracellular killing of Leishmania donovani by human monocyte-derived macrophages. J Exp Med 1987; 166: $1436-1446$.

14. Reed SG, Nathan CF, Pihl DL et al. Recombinant granulocyte macrophage colony-stimulating factor activates macrophages to inhibit Trypanosoma cruzi and release hydrogen peroxide. Comparison with interferon $\gamma . J \operatorname{Exp}$ Med 1987; 166: 1734-1746. 